\title{
Samambaias e licófitas em um afloramento rochoso costeiro no Estado do Rio de Janeiro, Brasil ${ }^{1}$
}

\author{
Fernanda Stefany Nunes Costa ${ }^{2,3,5}$, (1) Fábio de França Moreira ${ }^{3}$ e (1) Lana da Silva Sylvestre ${ }^{4}$
}

Submetido em 02.04.2020; aceito em 01.09.2020

Como citar: Costa, F.S.N., Moreira, F.F., \& Sylvestre, L.S. 2020. Samambaias e licófitas em um afloramento rochoso costeiro no Estado do Rio de Janeiro, Brasil. Hoehnea 47: e252020. http://dx.doi.org/10.1590/2236-8906-25/2020.

\begin{abstract}
Ferns and lycophytes from a costal inselberg of Rio de Janeiro State, Brazil). This study aimed to inventory the ferns and lycophytes of Morro do Pico $\left(22^{\circ} 56^{\prime} 05.2^{\prime \prime} \mathrm{S}, 43^{\circ} 07^{\prime} 13.8^{\prime \prime} \mathrm{W}\right)$, which is located in Fortes Environmental Protection Area, in the coastal region of Niterói, in Rio de Janeiro State, Brazil. This area is formed by a rocky outcrop and an adjacent Atlantic Forest remnant. Fieldworks were carried out from May to October 2014, the material was dried and incorporated to the Herbarium from Museu Nacional (R). The identification key is presented according to diagnostic morphological characters. We record ten families, distributed in fifteen genera and twenty-six species. Families with highest species richness were: Pteridaceae (10 spp.), Anemiaceae (four spp.) and Selaginellaceae (three spp.). The adjacent forest presents greater richness in relation to the inselberg. Among the taxa found only in this formation, it stands out Anemia tomentosa var. anthriscifolia, Doryopteris collina, Selaginella convoluta e S. sellowii.
\end{abstract}

Keywords: checklist, coastal vegetation, inselberg, pteridophytes

RESUMO - (Samambaias e licófitas em um afloramento rochoso costeiro no Estado do Rio de Janeiro, Brasil). O objetivo deste estudo foi realizar o levantamento de samambaias e licófitas do Morro do Pico (22 $\left.56^{\prime} 05.2^{\prime \prime} \mathrm{S}, 43^{\circ} 07^{\prime} 13.8^{\prime \prime} \mathrm{W}\right)$, que está localizado na Área de Proteção Ambiental dos Fortes, litoral do município de Niterói, Estado do Rio de Janeiro, Brasil. A área é formada por afloramentos rochosos e remanescentes de Mata Atlântica adjacente. As coletas foram realizadas entre o mês de maio a outubro de 2014, o material foi herborizado e depositado no herbário do Museu Nacional (R). A chave de identificação é apresentada com base em características morfológicas diagnósticas. Foram encontradas dez famílias, distribuídas em quinze gêneros, totalizando vinte e seis espécies. As famílias com maior riqueza foram Pteridaceae (10 spp.), Anemiaceae (quatro spp.) e Selaginellaceae (três spp.). A mata adjacente apresenta maior riqueza em relação ao inselberg. Dentre os táxons encontrados somente nesta formação, destacam-se Anemia tomentosa var. anthriscifolia, Doryopteris collina, Selaginella convoluta e S. sellowii.

Palavras-chave: inselberg, levantamento florístico, vegetação costeira, pteridófitas

\section{Introdução}

Inselbergs designam os afloramentos rochosos que emergem abruptamente da paisagem plana (Porembski 2007). Esses ambientes possuem características edáficas e microclimáticas peculiares, resultando em uma área de alta riqueza específica e número elevado de espécies endêmicas (Phillips 1982, Porembski 2000). O sudeste do Brasil é considerado um dos três hotspots de inselbergs, juntamente com Madagascar e o sudoeste da Austrália. Todos os centros de diversidade de inselbergs estão inseridos também em regiões de alta biodiversidade de importância global (Porembski 2007). No caso da região Sudeste do Brasil, está inserido no bioma Mata Atlântica, que é um dos

1. Parte do Trabalho de Conclusão de Curso da primeira Autora

2. Universidade Federal do Rio de Janeiro/Museu Nacional, Departamento de Botânica, Horto Botânico, Quinta da Boa Vista, s.n., São Cristóvão, 20940-040 Rio de Janeiro, RJ, Brasil

3. Faculdades Integradas Maria Thereza, Avenida Visconde do Rio Branco, 869, São Domingos, 24210-006 Niterói, RJ, Brasil

4. Universidade Federal do Rio de Janeiro, Instituto de Biologia, Departamento de Botânica, Avenida Carlos Chagas Filho 373, Prédio CCS - Bloco A, sala 1-88, Cidade Universitária, Ilha do Fundão, 21941-590 Rio de Janeiro, RJ, Brasil

5. Autora para correspondência: costa.fsn@gmail.com 
35 hotspots em biodiversidade (Mittermeier et al. 2004). Apesar de sua importância ecológica, historicamente, ainda há uma lacuna no conhecimento sobre dados florísticos e ecológicos dos inselbergs em várias regiões do mundo (Scarano 2007, de Paula et al. 2020).

Recentemente, foi publicado o checklist das plantas vasculares que ocorrem nos pães-de-açúcar no Sudeste do Brasil (incluindo o Sul da Bahia), numa área denominada Sugarloaf Land (de Paula et al. 2020). Neste estudo, foram listadas 46 espécies de samambaias e licófitas que ocorrem nesses afloramentos rochosos. Apesar da nossa área de estudo estar inserida no contexto do Sugarloaf land, não foram incluídas amostras do Morro do Pico.

No Estado do Rio de Janeiro foram realizados alguns levantamentos florísticos em afloramentos rochosos. Dentre estes, podem ser citados Carauta \& Oliveira (1984) no Morro da Urca, Pão de Açúcar e Cara de Cão, cidade do Rio de Janeiro; Santos \& Sylvestre (2006), na Pedra de Itacoatiara, no município de Niterói; Bovini et al. (2014) no Monumento Natural das Ilhas Cagarras; Mauad (2010) no Maciço do Itaoca, Norte fluminense; Meirelles et al. (1999) e Mauad (2013) em uma abrangência espacial mais ampla e em uma abordagem ecológica.

O Morro do Pico (Niterói, RJ, Brasil) possui um remanescente de Mata Atlântica ainda pouco estudado por botânicos e com escassez de coletas. Os trabalhos botânicos dessa área consistem em Trabalhos de Conclusão de Curso sobre estrato arbóreo-arbustivo (Paes 2013) e trepadeiras (Cunha 2017). Sendo assim, este estudo é o primeiro levantamento de samambaias e licófitas desse local.

Desta forma, o presente estudo teve como objetivo inventariar as espécies de samambaias e licófitas do Morro do Pico, uma área de afloramento rochoso e remanescente de Mata Atlântica, indicando o hábito, o ambiente preferencial e grau de ameaça das espécies que ocorrem na área, além de elaborar uma chave de identificação.

\section{Material e métodos}

Área de estudo - O Morro do Pico (22 $56^{\prime} 05.2^{\prime \prime S}$, $43^{\circ} 07^{\prime} 13.8^{\prime \prime} \mathrm{W}$ ) está localizado no Estado do Rio de Janeiro, município de Niterói, e está inserido na Área de Proteção Ambiental (APA) do Morro do Morcego, da Fortaleza de Santa Cruz e dos Fortes do Pico e do Rio Branco (também conhecida como APA dos Fortes) (figura 1).

A APA dos Fortes foi criada em 2011, pelo decreto $n^{\circ}$ 10912/2011 (Niterói 2011) devido a sua grande importância cultural e histórica, além de abrigar remanescentes de Mata Atlântica. Atualmente os fortes estão sob a jurisdição do $21^{\circ}$ Grupo de Artilharia de Campanha do Exército Brasileiro (Barreto 1958, Comando Militar do Leste 2014).

O Morro do Pico é um afloramento rochoso com vegetação típica de inselbergs circundado pela floresta ombrófila densa submontana (Veloso et al. 1991), no domínio da Mata Atlântica. Neste estudo, foram incluídos os afloramentos rochosos e a mata adjacente que constituem este morro.
As rochas desta área são do tipo metamórfica, pertencente à unidade gnaisse facoidal, sendo muito é comum nos municípios do Rio de Janeiro e Niterói, principalmente nos afloramentos rochosos costeiros (Almeida \& Almeida 2012, Silva et al. 2013). Em relação ao relevo, o Morro do Pico possui $221 \mathrm{~m}$ de altitude, com paredões de afloramentos rochosos e encostas com coberturas de sedimentos (Niterói 2011). A APA dos Fortes tem um clima úmido tropical com temperatura média anual de $22^{\circ} \mathrm{C}$, a média anual de chuvas varia de 1100 a $1800 \mathrm{~mm}$, apresentando um microclima típico de área litorânea, com grande influência das brisas marítimas e terrestres (Niterói 2011, Silva et al. 2013).

Coleta de dados - Foram realizadas coletas bimestrais entre maio e outubro de 2014, abrangendo a estrada principal, trilhas e incursões assistemáticas em trechos da floresta. O material testemunho coletado foi herborizado segundo técnicas usuais para samambaias (Windisch 1992) e incorporado ao herbário do Museu Nacional do Rio de Janeiro (R). Para observação e análise de coleções pretéritas, foram consultados os herbários R, RB e RFFP, (acrônimos segundo Index Herbariorum [Thiers, continuamente atualizado]), além dos herbários virtuais através das plataformas INCT - Herbário Virtual da Flora e dos Fungos e Reflora - Lista da Flora do Brasil. As plantas foram identificadas por meio da literatura específica para cada família e a classificação seguiu PPG I (2016).

As espécies foram classificadas quanto às seguintes categorias de forma de vida e substrato: rupícola, terrícola, holoepífita, epífita facultativa e trepadeira. Quanto ao ambiente, as espécies foram encontradas em afloramento rochoso, no interior/borda de mata e nas ruínas dos fortes.

A chave de identificação foi elaborada com base nas principais características diagnósticas entre os táxons.

\section{Resultados e Discussão}

Foram encontradas dez famílias, distribuídas em quinze gêneros, totalizando 26 espécies. Destas, 23 são samambaias e três são licófitas (tabela 1). Na consulta aos herbários, foi localizado apenas um registro anterior a este trabalho, Selaginella sulcata (Desv. ex Poir.) Spring ex Mart. depositada no herbário RFFP, com duplicata no RB.

As famílias de pteridófitas com maior riqueza específica foram Pteridaceae (10 spp), Anemiaceae (quatro spp) e Selaginellaceae (três spp). Essas famílias também são apontadas como as mais ricas nos afloramentos do Sudeste do Brasil segundo o estudo de Paula et al. (2020). Os gêneros com maior riqueza específica foram Anemia Sw. (quatro spp), Pteris L. (quatro spp), Doryopteris J.Sm. (três spp), Selaginella P.Beauv. (três spp) e Blechnum L. (duas spp).

Quanto ao hábito, a maioria das espécies é terrícola, ocorrendo na área ocupada pela floresta. As espécies com hábito rupícola correspondem a $34 \%$, crescendo sobre os afloramentos rochosos, nos muros das ruínas e em rochas no interior da mata. Foram encontradas apenas duas espécies epífitas: Microgramma vacciniifolia, que foi caracterizada 
Tabela 1. Espécies de samambaias e licófitas do Morro do Pico, Niterói, Estado do Rio de Janeiro, Brasil.

Table 1. Ferns and lycophytes from Morro do Pico, Niterói, Rio de Janeiro State, Brazil.

\begin{tabular}{|c|c|c|c|}
\hline Família e espécie & $\begin{array}{l}\text { Forma de vida } \\
\text { e substrato }\end{array}$ & Ambiente & Voucher \\
\hline \multicolumn{4}{|l|}{ Anemiaceae } \\
\hline Anemia collina Raddi & Terrícola & $\begin{array}{l}\text { Interior e borda de } \\
\text { mata }\end{array}$ & $\begin{array}{l}\text { Costa et al. } 49 ; \\
67 ; 72\end{array}$ \\
\hline Anemia hirsuta (L.) Sw. & Terrícola & Borda da mata & Costa et al. 73 \\
\hline Anemia tomentosa var. anthriscifolia (Schrader) Mickel & Rupícola & Afloramento rochoso & $\begin{array}{l}\text { Costa et al. } 57 \\
71 ; 74 ; 78 ; 79\end{array}$ \\
\hline Anemia villosa Humb. \& Bonpl. ex Willd. & Rupícola & Afloramento rochoso & Costa et al. 75 \\
\hline \multicolumn{4}{|l|}{ Aspleniaceae } \\
\hline Asplenium brasiliense $\mathrm{Sw}$. & Terrícola & Interior da mata & Costa et al. 82 \\
\hline \multicolumn{4}{|l|}{ Blechnaceae } \\
\hline Blechnum occidentale L. & Terrícola & Borda da mata & Costa et al. 62 \\
\hline Blechnum polypodioides Raddi & Terrícola & Borda da mata & Costa et al. 64 \\
\hline \multicolumn{4}{|l|}{ Dryopteridaceae } \\
\hline Ctenitis falciculata (Raddi) Ching & Terrícola & Borda da mata & Costa et al. 56 \\
\hline \multicolumn{4}{|l|}{ Lygodiaceae } \\
\hline Lygodium volubile $\mathrm{Sw}$. & Trepadeira & Borda da mata & Costa et al. 52 \\
\hline \multicolumn{4}{|l|}{ Nephrolepidaceae } \\
\hline Nephrolepis pendula (Raddi) J.Sm. & Epífita & Interior da mata & Costa et al. 61 \\
\hline \multicolumn{4}{|l|}{ Polypodiaceae } \\
\hline Microgramma vacciniifolia (Langsd. \& Fisch.) Copel. & $\begin{array}{l}\text { Epífita/ } \\
\text { rupícola }\end{array}$ & Borda da mata & Costa et al. 53 \\
\hline Serpocaulon triseriale (Sw.) A.R.Sm. & Rupícola & Afloramento rochoso & Costa et al. 66; 85 \\
\hline \multicolumn{4}{|l|}{ Pteridaceae } \\
\hline Adiantopsis radiata $(\mathrm{L}$.$) Fée$ & Terrícola & Interior de mata & Costa et al. 51 \\
\hline Adiantum raddianum C. Presl & Rupícola & $\begin{array}{l}\text { Ruínas do forte } \\
\text { (muro) }\end{array}$ & Costa et al. 76 \\
\hline Doryopteris collina (Raddi) J.Sm. & Rupícola & Afloramento rochoso & Costa et al. 54 \\
\hline Doryopteris concolor (Langsd. \& Fisch.) Kuhn & Terrícola & Interior de mata & Costa et al. $58 ; 70$ \\
\hline Doryopteris varians (Raddi) J.Sm. & Terrícola & Borda da mata & Costa et al. 86 \\
\hline Hemionitis tomentosa (Lam.) Raddi & $\begin{array}{l}\text { Rupícola/ } \\
\text { terrícola }\end{array}$ & Borda da mata & Costa et al. 60; 63 \\
\hline Pteris ensiformis Burm. f. & Terrícola & Borda da mata & Costa et al. 68 \\
\hline Pteris leptophylla $\mathrm{Sw}$. & Terrícola & Borda da mata & Costa et al. 69 \\
\hline Pteris splendens Kaulf. & Terrícola & Interior de mata & Costa et al. 84 \\
\hline Pteris vittata $\mathrm{L}$. & Rupícola & $\begin{array}{l}\text { Ruínas do forte } \\
\text { (muro) }\end{array}$ & Costa et al. 81 \\
\hline \multicolumn{4}{|l|}{ Selaginellaceae } \\
\hline Selaginella convoluta (Arn.) Spring & Rupícola & Afloramneto rochoso & Costa et al. 55 \\
\hline Selaginella sellowii Hieron. & Rupícola & Afloramento rochoso & Costa et al. 59 \\
\hline Selaginella sulcata (Desv. ex Poir.) Spring ex Mart. & Terrícola & Interior da mata & $\begin{array}{l}\text { Costa et al. 50; } \\
65 ; \text { Barros } 4914\end{array}$ \\
\hline \multicolumn{4}{|l|}{ Thelypteridaceae } \\
\hline Christella dentata (Forssk.) Brownsey \& Jermy & Rupícola & $\begin{array}{l}\text { Ruínas do forte } \\
\text { (muro) }\end{array}$ & Costa et al. 77 \\
\hline
\end{tabular}




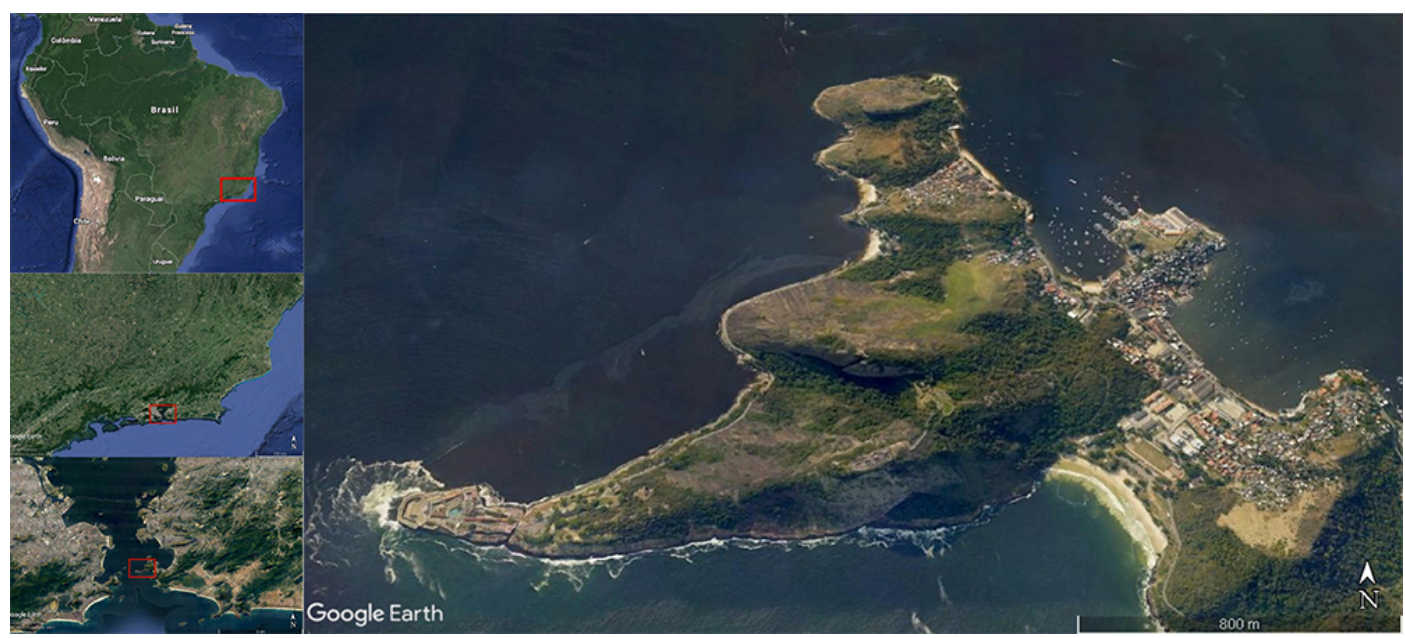

Figura 1: Área de estudo. Morro do Pico (22 56' 05.2" S, 43 07' 13.8" W), localizado na APA Morro do Morcego, da Fortaleza de Santa Cruz e dos Fortes do Pico e do Rio Branco, município de Niterói, RJ, Brasil.

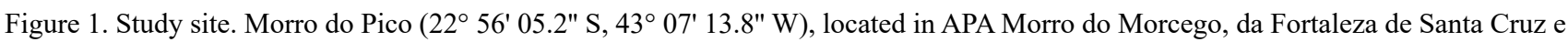
dos Fortes do Pico e do Rio Branco, municipality of Niterói, Rio de Janeiro State, Brazil.

como uma epífita facultativa, pois também ocorria sobre rochas, e Nephrolepis pendula, como holoepífita. A única espécie trepadeira encontrada foi Lygodium volubile, bastante comum em bordas de trilhas, onde ocorriam muitas plântulas desta espécie.

A floresta abriga a maior riqueza de samambaias e licófitas, onde ocorrem cerca de $80 \%$ das espécies de encontradas na área. A menor diversidade nos afloramentos rochosos é explicada por fatores ambientais, como baixa umidade, pouca disponibilidade de água, escassez de solo e nutrientes e alta exposição à luz solar e ao vento (Porembski 2007). Apesar da menor riqueza, os afloramentos rochosos são considerados áreas prioritárias para conservação, pois a vegetação possui maior fragilidade frente aos impactos ambientais devido à especificidade do ecossistema. As principais ameaças antrópicas são os incêndios, a extração de rochas, a especulação imobiliária, o turismo e a introdução de espécies invasoras (Porembski 2000, Porembski 2007, Aximoff et al. 2016). Entretanto, pela área estar incluída em um local protegido pelas forças armadas, os impactos sofridos foram aparentemente mínimos, especialmente por serem sítios históricos.

Em relação ao ambiente preferencial, $41 \%$ das espécies foram registradas para a borda das trilhas, enquanto $26 \%$ foram coletadas no interior da floresta, $22 \%$ crescem sobre matriz rochosa dos afloramentos e $11 \%$ ocorrem sobre os muros de pedras nas ruínas do forte.

A composição florística das samambaias e licófitas nos inselbergs difere da mata adjacente (Meirelles et al. 1999). Nos afloramentos rochosos, encontram-se espécies típicas deste ambiente, como Anemia tomentosa var. anthriscifolia, Doryopteris collina, Selaginella convoluta e S. sellowii (figura 2). Estas espécies apresentam características morfológicas que conferem a estas plantas a resistência necessária para o desenvolvimento em um ambiente com alta restrição hídrica (Meirelles et al. 1999). As espécies do gênero Selaginella são poiquilohídricas, isto é, podem perder grande quantidade de água e até mesmo a coloração, voltando a hidratar-se completamente após as primeiras chuvas,

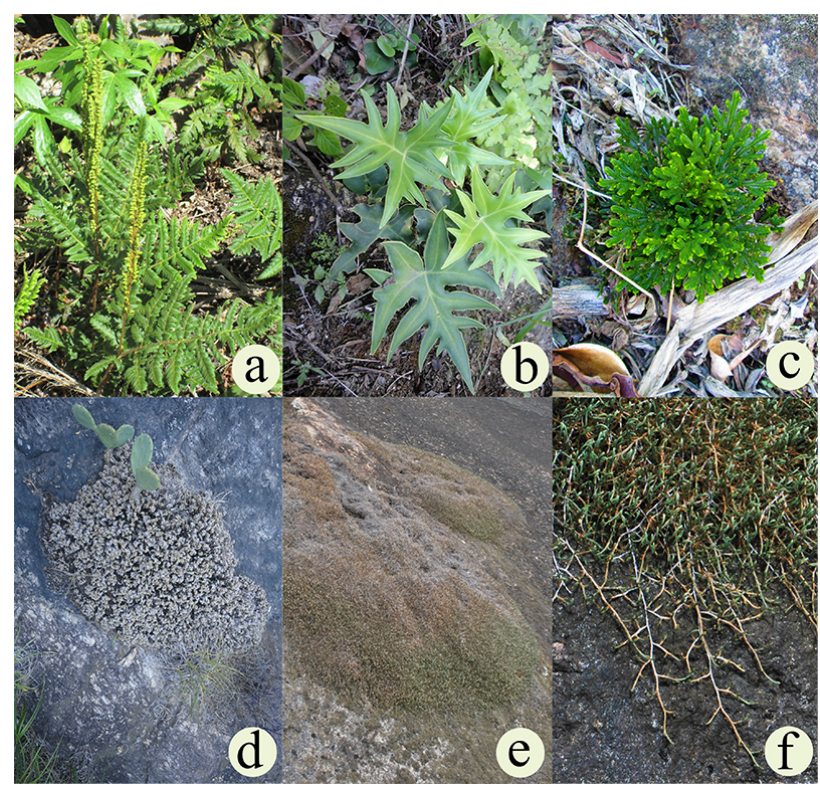

Figura 2. Samambaias e licófitas do Morro do Pico, Niterói, RJ, Brasil. a. Anemia tomentosa var. anthriscifolia (Schrader) Mickel. b. Doryopteris collina (Raddi) J.Sm. c. Selaginella convoluta (Arn.) Spring hidratada. d. Selaginella convoluta seca. e. Selaginella sellowii Hieron. em formação de tapete. G. Selaginella sellowii em detalhe.

Figure 2. Ferns and lycophytes of Morro do Pico, Niterói, Rio de Janeiro State, Brazil. a. Anemia tomentosa var. anthriscifolia (Schrader) Mickel. b. Doryopteris collina (Raddi) J.Sm. c. Selaginella convoluta (Arn.) Spring hydrated. d. Selaginella convoluta dried. e. Selaginella sellowii Hieron., mats. f. Selaginella sellowii, in detail. 
retomando seu metabolismo (Porembski \& Barthlott 2000, Porembski 2007). Anemia tomentosa var. anthriscifolia é densamente revestida por tricomas e Doryopteris collina possui folhas coriáceas. Essas características, segundo Dickinson (2000), são adaptações para o ambiente rochoso. Todas estas espécies podem formar "ilhas de vegetação" sobre rochas expostas, com diferentes graus de inclinação, juntamente com espécies de Cactaceae e Veloziaceae. Diferente das demais, Selaginella sellowii, cresce em tapetes sobre solo muito raso, formando comunidades monoespecíficas (Meirelles et al. 1999).

Apesar das espécies Anemia collina, Doryopteris varians e Microgramma vacciniifolia ocorrerem em inselbergs do Sudeste brasileiro (de Paula et al. 2020), essas não foram encontradas no Morro Pico em afloramentos rochosos, e sim no interior e borda da mata adjacente. Nas áreas mais antropizadas, como ao longo da estrada e nas ruínas dos fortes, são encontradas espécies naturalizadas como Christella dentata, Pteris vittata e Pteris ensiformis. A espécie Christella dentata tem distribuição paleotropical e foi naturalizada na região neotropical (Holttum 1983). Pteris vittata é subespontânea, tem origem no Velho Mundo e foi introduzida nas Américas, onde pode ser encontrada em muros, calçadas e construções na cidade (Prado \& Windisch 2000). Já Pteris ensiformis, embora também seja subespontânea, é amplamente cultivada devido a beleza de suas folhas variegadas (Prado \& Windisch 2000, Chao et al. 2014).

A única espécie endêmica do Brasil é Pteris leptophylla, que ocorre na Floresta Atlântica, preferencialmente áreas costeiras, margem de rios e córregos e locais úmidos e sombreados (Prado \& Windisch 2000). No Morro do Pico, é uma planta terrícola que cresce no interior da mata.

O padrão de altas taxas de endemismo nos inselbergs observado em angiospermas (Meirelles et al. 1999, de Paula et al. 2020), não foram encontrados para a flora de samambaias e licófitas tanto no Morro do Pico, quanto na Pedra de Itacoatiara, Niterói-RJ (Santos \& Sylvestre, 2006). Nenhuma das espécies inventariadas neste estudo está categorizada como ameaçada.

Chave de identificação para as samambaias e licófitas do Morro do Pico, Niterói, Estado do Rio de Janeiro

1. Plantas com microfilos (lâmina foliar até $1 \mathrm{~cm}$ de comp., uninérvia)

2. Microfilos isomorfos, dispostos em espiral ao longo do caule Selaginella sellowii

2. Microfilos heteromorfos, dispostos lateralmente e dorsiventralmente no caule

3. Microfilos em roseta Selaginella convoluta

3. Microfilos não dispostos em roseta Selaginella sulcata

1. Plantas com megafilos (lâmina foliar maior que $1 \mathrm{~cm}$ de comp., nervuras ramificadas)

4. Esporângios com ânulo apical

5. Plantas trepadeiras; esporângios localizados em segmentos na margem das folhas Lygodium volubile

5. Plantas não trepadeiras; esporângios em um par de pinas basais modificadas

6. Base da lâmina pinada; caule ereto ou ascendente Anemia collina

6. Base da lâmina pinada-pinatífida ou bipinada; caule ascendente ou reptante

7. Caule ascendente Anemia villosa

7. Caule reptante

8. Lâmina pinada-pinatífida, membranácea Anemia hirsuta

8. Lâmina bipinada, coriácea Anemia tomentosa var. anthriscifolia

4. Esporângio com ânulo longitudinal

9. Soros marginais

10. Soros lineares

11. Lâmina foliar inteira, pedada

12. Nervuras livres Doryopteris concolor

12. Nervuras areoladas

13. Pecíolo cilíndrico, nigrescente; últimos segmentos deltóides Doryopteris varians

13. Pecíolo achatado na porção distal, castanho; últimos segmentos ovados a lanceolados Doryopteris collina

11. Lâmina foliar pinada

14. Folhas heteromorfas, variegadas Pteris ensiformis

14. Folhas monomorfas, completamente verdes ou raramente variegadas 
15. Lâmina bipinada, membranácea Pteris leptophylla

15. Lâmina pinada, cartácea a coriácea

16. Pinas estreitas, ca. $1 \mathrm{~cm}$ de larg.; nervuras livres Pteris vittata

16. Pinas mais largas, ca. $2 \mathrm{~cm}$ larg.; nervuras areoladas Pteris splendens

10. Soros não lineares

17. Lâmina com pinas radiadas Adiantopsis radiata

17. Lâmina tripinada Adiantum raddianum

9. Soros dorsais

18. Soros com indúsio

19. Lâmina pinada; soros paralelos à costa

20. Lâmina linear-lanceolada a elíptica; pina basal reduzida à aurícula Blechnum polypodioides

20. Lâmina deltoide; pina basal não reduzida a aurícula Blechnum occidentale

19. Lâmina inteira; soros ao longo das nervuras secundárias Asplenium brasiliense

18. Soros sem indúsio

21. Soros alongados, dispostos sobre as nervuras Hemionitis tomentosa

21. Soros arredondados

22. Caule reptante; pecíolo articulado ao caule

23. Lâmina simples, dimorfa Microgramma vaccinifolia

23. Lâmina pinada, monomorfa Serpocaulon triseriale

22. Caule ereto ou, se reptante, pecíolo não articulado ao caule

24. Planta epífita; lâmina pinada Nephrolepis pendula

24. Planta terrícola; lâmina pinado-pinatífida

25. Pecíolo com dois feixes vasculares Christella dentata

25. Pecíolo com mais de dois feixes vasculares Ctenitis falciculata

\section{Conclusões}

Os afloramentos rochosos costeiros são considerados áreas prioritárias para conservação por abrigarem uma flora altamente adaptada às condições extremas impostas por este ambiente, tais como alta insolação, pouca disponibilidade de solo e elevados níveis de salinidade. Dentre os táxons encontrados somente nesta formação, Anemia tomentosa var. anthriscifolia, Doryopteris collina, Selaginella convoluta e $S$. sellowii crescem em populações densas nos locais mais expostos, possuindo caracteres morfológicos como poiquilohidria, alto revestimento de tricomas e folhas coriáceas ou extremamente reduzidas. Estes atributos funcionais facilitam o estabelecimento e desenvolvimento destas plantas neste ambiente tão inóspito, compondo a peculiar flora dos costões rochosos costeiros.

Já a formação florestal apresenta características ambientais mais favoráveis para o estabelecimento de samambaias e licófitas, sendo assim, a mata circundante apresenta maior riqueza em relação ao inselberg.

Este estudo contribuiu para conhecimento das samambaias e licófitas de afloramentos rochosos, preenchendo uma lacuna de uma área até então não inventariada e com pouquíssimas coletas. Apesar do aumento das pesquisas em inselbergs nos últimos anos, ainda são necessários mais inventários florísticos para que futuramente seja possível a realização de trabalhos comparativos entre esses ambientes.

\section{Agradecimentos}

Os autores agradecem ao $21^{\circ}$ Grupo de Artilharia do Exército, pela autorização de coleta e pelo apoio logístico durante o trabalho de campo na área.

\section{Literatura citada}

Almeida, S. \& Almeida, C.M. 2012. Fortaleza de Santa Cruz: Patrimônio Histórico e Geológico de Niterói, RJ. Anuário do Instituto de Geociências 35: 222-235.

Aximoff, I.A., Bovini, M.G. \& Fraga, C.N. 2016. Vegetação em afloramentos rochosos litorâneos perturbados por incêndios na Região Metropolitana Fluminense, estado do Rio de Janeiro. Biodiversidade Brasileira 6: 149-172.

Barreto, A. 1958. Fortificações no Brasil (Resumo Histórico). Rio de Janeiro: Editora Biblioteca do Exército.

Bovini, M.G., Faria, M., Oliveira, R.R. \& Kurtz, B.C. 2014. Floristic diversity of the Cagarras Islands Natural Monument, Rio de Janeiro, Brazil. Check List 10: 366373. 
Carauta, J.P.P. \& Oliveira, R.R.O. 1984. Plantas vasculares dos morros da Urca, Pão de Açúcar e Cara de Cão. Rodriguésia 36: 13-24.

Chao, Y.S, Rouhan, G., Amoroso, V.B., Chiou, W.L. 2014. Molecular Phylogeny and Biogeography of the fern genus Pteris (Pteridaceae). Annals of Botany 114: 109-124.

Comando Militar do Leste. 2014. Fortes e Fortalezas. Disponível em http://www.cml.eb.mil.br/fortes-efortalezas/niteroi-rj.html (acesso em 18-IX-2017).

Cunha, L.S. 2017. Levantamento florístico de trepadeiras na Área de Proteção Ambiental dos Fortes, Niterói, RJ, Brasil. Trabalho de Conclusão de Curso, Universidade do Estado do Rio de Janeiro, São Gonçalo.

De Paula, L.F.A., Azevedo, L.O., Mauad, L.P., Cardoso, L.J.T., Braga, J.M.A., Kollmann, L.J.C., Fraga, C.N., Menini Neto, L., Labiak, H.P., Mello-Silva, R., Porembski, S. \& Forzza, R.C. 2020. Sugarloaf Land in south-eastern Brazil: a tropical hotspot of lowland inselberg plant diversity. Biodiversity Data Journal 8: e53135.

Dickinson, W.C. 2000. Integrative Plant Anatomy. Harcourt Academic Press, San Diego.

Holttum, R.E. 1983. The family Thelypteridaceae in Europe. Acta Botánica Malacitana 8: 47-58.

Instituto Nacional de Ciência e Tecnologia, Herbário Virtual da Flora e Fungos. In: Centro de Referência em Informação Ambiental. Disponível em http://splink. cria.org.br/ (acesso em 8-V-2020).

Mauad, L.P. 2010. Levantamento florístico de um remanescente florestal de Mata Atlântica no Morro do Itaoca, Campos dos Goytacazes, RJ. Trabalho de Conclusão de Curso, Universidade Estadual do Norte Fluminense Darcy Ribeiro, Campos dos Goytacazes.

Mauad, L.P. 2013. Comunidades vegetais em pães-deaçúcar no Estado do Rio de Janeiro. Dissertação de Mestrado, Universidade do Estado do Rio de Janeiro, Rio de Janeiro.

Meirelles, S.T., Pivello, V.R. \& Joly, C.A. 1999. The vegetation of granite rock outcrops in Rio de Janeiro, Brazil, and the need for its protection. Environmental Conservation 26: 10-20.

Mittermeier, R.A., Robles Gil, P., Hoffmann, M., Pilgrim, J., Brooks, T., Mittermeier, C.G., Lamoreux, J. \& Fonseca, G.A.B. 2004. Hotspots revisited: Earth's biologically richest and most endangered terrestrial ecoregions. Cemex, Washington.

Niterói. 2011. Decreto N 10912/2011 de 20-III-2011. Plano de Manejo da Área de Proteção Ambiental do Morro do Morcego, da Fortaleza de Santa Cruz e dos Fortes do Pico e do Rio Branco. Diário oficial do Município de Niterói, atos do prefeito, 23-III-2011, pp. 1-17.
Paes, G.C.L. 2013. Levantamento florístico do estrato arbóreo-arbustivo do Morro do Forte do Pico, Área de Proteção Ambiental dos Fortes, Niterói, RJ, Brasil. Trabalho de Conclusão de Curso, Universidade Federal Fluminense, Niterói.

Phillips, D.L. 1982. Life-forms of granite outcrop plants. American Midland Naturalist Journal 107: 206-208.

Porembski, S. 2000. The invasibility of tropical granite outcrops ('inselbergs') by exotic weeds. Journal of the Royal Society of Western Australia 83:131-137.

Porembski, S. 2007. Tropical inselbergs: habitat types, adaptative strategies and diversity patterns. Revista Brasileira de Botânica 30: 579-589.

Porembski, S. \& Barthlott, W. 2000. Inselbergs: biotic diversity of isolated rock outcrops in tropical and temperate regions. Ecological Studies. v. 146. SpringerVerlag, Berlim.

PPG I. 2016. A community-derived classification for extant lycophytes and ferns. Journal of Systematics and Evolution 54: 563-603.

Prado, J. \& Windisch, P.G. 2000. The genus Pteris L. (Pteridaceae) in Brazil. Boletim do Instituto de Botânica 13: 103-199.

Reflora - Herbário Virtual. Disponível em http://reflora. jbrj.gov.br/reflora/herbarioVirtual/ (acesso em 22-VI2020).

Santos, M.G. \& Sylvestre, L.S. 2006. Aspectos florísticos e econômicos das pteridófitas de um afloramento rochoso do Estado do Rio de Janeiro, Brasil. Acta Botanica Brasilica 20: 115-124.

Scarano, F.R. 2007. Rock outcrop vegetation in Brazil: a brief overview. Revista Brasileira de Botânica 30: 561-568.

Silva, M.A.M., Batista Neto, J.A., Smith, B., Mcalister, J., Warke, P. \& Curran, J. 2013. Intemperismo decorrente da acumulação de sal e a formação de alvéolos e tafoni nos afloramentos das praias de Niterói (Rio de Janeiro, Brasil). Revista Brasileira de Geomorfologia 14: 189195.

Thiers, B. 2020. (atualização continua). Index Herbariorum: A global directory of public herbaria and associated staff. New York Botanical Garden's Virtual Herbarium. Disponível em http://sweetgum.nybg.org/ih/ (acesso em 12-XII-2018).

Veloso, H.P., Rangel-Filho, A.L.R. \& Lima, J.C.A. 1991. Classificação da Vegetação Brasileira, adaptada a um sistema universal. IBGE, Departamento de Recursos Naturais e Estudos Ambientais. Rio de Janeiro.

Windisch, P.G. 1992. Pteridófitas da região Norte-ocidental do Estado de São Paulo: guia para estudo e excursões. $2^{\mathrm{a}}$ edição. Universidade Estadual Paulista, São José do Rio Preto. 